\title{
Estimation of interfacial proton conductivity by effective media approximation for sheet-like composite electrolyte prepared from poly(2-acrylamido-2-methyl-1-propanesulfonic acid)- deposited core-shell particles
}

\author{
Hisatoshi SAKAMOTo, ${ }^{*}$ Yusuke DAIKo, ${ }^{* *}$ Hiroyuki MUTO ${ }^{*, * *}$ and Atsunori MATSUDA ${ }^{*, * *, \dagger}$ \\ *Department of Environmental and Life Sciences, Toyohashi University of Technology, \\ 1-1 Hibarigaoka, Tempaku, Toyohashi, Aichi 441-8580 \\ ** Department of Materials Science and Chemistry, University of Hyogo, Shosha, Himeji, Hyogo 670-2101 \\ *** Department of Electrical and Electronic Information Engineering, Toyohashi University of Technology, \\ 1-1 Hibarigaoka, Tempaku, Toyohashi, Aichi 441-8580
}

\begin{abstract}
Proton conductive poly(2-acrylamido-2-methyl-1-propanesulfonic acid) (PAMPS) ultrathin film was deposited as a multilayer on the size-controlled phenylsilsesquioxane $\left(\mathrm{PhSiO}_{3 / 2}\right)$ particles via layer-by-layer $(\mathrm{LbL})$ assembly. The composite electrolyte prepared from the PAMPS-multilayer deposited $\mathrm{PhSiO}_{3 / 2}$ had a grain boundary composed of the proton conductive multilayer. The interfacial conducting path having a honeycomb structure was percolated in the composite. The conductivity of the interfacial conducting path was estimated from general effective media (GEM) approximation. The interfacial conductivities of the composite under the conditions of 70 and $95 \%$ R.H. at $80^{\circ} \mathrm{C}$ were calculated from the fitting by GEM approximation to be 0.03 and $0.2 \mathrm{~S} \mathrm{~cm}^{-1}$, respectively.
\end{abstract}

(2011 The Ceramic Society of Japan. All rights reserved.

Key-words : Layer-by-Layer, Core-shell particle, Proton conductivity, Percolation, Effective media approximation

[Received June 30, 2011; Accepted August 24, 2011]

\section{Introduction}

Fast-ion, such as proton $\left(\mathrm{H}^{+}\right)$, oxide ion $\left(\mathrm{O}^{2-}\right)$, lithium ion $\left(\mathrm{Li}^{+}\right)$and hydroxide ion $\left(\mathrm{OH}^{-}\right)$, conductors are key-materials to improve the performances for electrochemical devices such as polymer electrolyte membrane fuel cell, solid oxide fuel cell, lithium-ion battery and metal-air battery. Liang first reported in 1973 that lithium ion conductivity was increased more than one order of magnitude by dispersing of $\mathrm{Al}_{2} \mathrm{O}_{3}$ particles in lithium iodide. ${ }^{1)}$ Such enhancement of ionic conductivity depended on the $\mathrm{Al}_{2} \mathrm{O}_{3}$ particles size and concentration of dispersed materials, and the increase of ionic defects at the hetero-interface between the $\mathrm{Al}_{2} \mathrm{O}_{3}$ particle and $\mathrm{LiI}$ matrix was considered to cause the enhancement of the $\mathrm{Li}$ ion conductivity. ${ }^{2), 3)}$ Since then, there has been a growing interest in the ion conduction of the composite electrolyte. Several kinds of composite materials, such as $\mathrm{AgI}-\mathrm{TiO}_{2},{ }^{4)}$ poly(ethylene oxide) $-\mathrm{LiClO}_{4}-\mathrm{TiO}_{2},{ }^{5} \mathrm{CuBr}-$ $\left.\mathrm{Al}_{2} \mathrm{O}_{3},{ }^{6}\right) \mathrm{LiZnI}_{4}-\mathrm{Al}_{2} \mathrm{O}_{3},{ }^{7)}$ and poly(vinylidene fluoride-co-hexafluoropropylene)- $\mathrm{BaTiO}_{3},{ }^{8)}$ demonstrated the enhancement of the ionic conductivity, so far.

The ion conductivity of the composites drastically increases at the percolation threshold and the composites change to be ion conductors from insulators. The conductivities of the composites increase in proportion to the amount of ion conducting materials according to the mixing rule, in addition the enhancement of the overall ion conduction occurs for the composite materials. The percolation of conducting-path network is the most important to enhance the ion conductivity for the composite materials, and it is

Corresponding author: A. Matsuda; E-mail: matsuda@ee.tut.ac.jp related with the volume fraction, size, aspect ratio and dispersibility of fillers as ion-conducting additives. In the past, mechanical mixing was generally employed as the preparation procedure of composite materials. On the other hand, layer-by-layer (LbL) assembly is a convenient technique to prepare the highly dispersed inorganic-organic composite electrolytes at ordinary temperature and atmospheric pressure. LbL assembly uses the electrostatic interaction between the polycations and the polyanions in aqueous solutions as a driving force of assembly. LbL assembly has been also employed to form the polymer electrolytes for fuel cells, such as sulfonated poly(2,6-dimethyl 1,4-phenylene oxide) (sPPO)/Polycations ${ }^{9)}$ and Keggin-ion/Polycation. ${ }^{10)}$

We previously reported that proton-conductive ultrathinfilms of poly(2-acrylamido-2-methyl-1-propanesulfonic acid) (PAMPS) were highly dispersed and connected in non-protonconducting silsesquioxane matrix by a novel composite procedure using LbL assembly. ${ }^{11)-13)}$ Sol-gel derived phenylsilsesquioxane $\left(\mathrm{PhSiO}_{3 / 2}\right)$ particles have plastic/thermal deformation property, so that a monolithic composite electrolyte was prepared from PAMPS-multilayer-coated core-shell $\mathrm{PhSiO}_{3 / 2}$ particles by hot-pressing. Ultrathin PAMPS-multilayers on the particles as the shell were connected and concentrated at the particle interfaces in the composite. The proton conductivity of the composite electrolyte significantly increased with very small amounts of the ion conductive multilayer.

In this study, the proton conductivity of the percolated PAMPSmultilayer in the composite has been discussed from the mathematical calculation using a percolation model. For instance, the numerical analyses based on random-resister network model, ${ }^{14), 15)}$ Monte Carlo simulations, ${ }^{15), 16)}$ and effective medium 
approximations (EMA), ${ }^{17}$ have been preformed for the simulation of the macroscopic ion conduction of the composite materials. A general effective media (GEM) approximation including the percolation theory was reported by McLachlan et al. to improve the approximate accuracy near the percolation threshold. ${ }^{18), 19)}$ It was found that the empirical formulae such as the parallel approximation, the logarithmic mixing rule and the mixing rule were not suitable to present the composition dependence of conductivity of the composite, which showed a remarkable change at the percolation threshold. Therefore, GEM, in which percolation threshold value and the tendency of the conductivity changes can be arbitrarily selected, was adopted to analyze the composition dependence. The GEM equation successfully simulated conductivity changes for AgI-BN, ${ }^{20)} \mathrm{AgI}-\mathrm{Ag}_{2} \mathrm{O}-\mathrm{B}_{2} \mathrm{O}_{3},{ }^{21)}$ $\mathrm{Ag}_{4} \mathrm{RbI}_{5}-\mathrm{AgI}{ }^{22)}$ and $\mathrm{Y}_{2} \mathrm{O}_{3}-\mathrm{ZrO}_{2}{ }^{23)}$ In the present study, the proton conductivity of the percolated PAMPS-multilayer in the composite was estimated from the fitting of volume fraction dependence of conductivity using the GEM approximation. The volume fraction of the PAMPS-multilayer in the composite was controlled by the change of the $\mathrm{PhSiO}_{3 / 2}$ particle diameter.

\section{Experimental}

\subsection{Preparation of the multilayer-percolated com- posite}

Poly(diallyldimethylammonium chloride) (PDDA, average $\mathrm{Mw}=100,000-200,000 \mathrm{~g} \mathrm{~mol}^{-1}$, Aldrich), poly(sodium 4-styrenesulfonate) (PSS, average $\mathrm{Mw}=70,000 \mathrm{~g} \mathrm{~mol}^{-1}$, Aldrich), and poly(2-acrylamido-2-methyl-1-propanesulfonic acid) (PAMPS, average $\mathrm{Mw}=2,000,000 \mathrm{~g} \mathrm{~mol}^{-1}$, Aldrich) were used as purchased. PDDA is polycationic in aqueous solution, and PSS and PAMPS are polyanionic. Figure 1 shows the molecular structures of the polycation and polyanions. $0.5 \mathrm{M}$ sodium chloride $(\mathrm{NaCl})$ was added in all polymer solutions to increase the adsorbed amounts of the polymer electrolytes. The concentrations of polymer solutions were $1.0 \mathrm{mg} / \mathrm{mL}$ for PDDA and PSS, and $3.0 \mathrm{mg} / \mathrm{mL}$ for PAMPS. The size-controlled $\mathrm{PhSiO}_{3 / 2}$ particles with a PDDA(+)/PSS(-)/PDDA(+)/PAMPS(-) multilayer were prepared in the same preparation procedure described in our previous paper. ${ }^{13)}$ The PDDA/PSS/PDDA-multilayer was a primer layer for the subsequent PAMPS deposition.

The composite electrolytes were prepared from the multilayerdeposited $\mathrm{PhSiO}_{3 / 2}$ by uniaxial pressing under $600 \mathrm{MPa}$ for $5 \mathrm{~min}$ at room temperature and then hot-pressing under $2 \mathrm{MPa}$ at $120^{\circ} \mathrm{C}$ for $1 \mathrm{~min}$. The conductivity of the composite electrolyte was determined from Cole-Cole plots measured by an AC impedance method using an impedance analyzer (SI 1260, Solartron). Gold electrodes $\left(0.07 \mathrm{~cm}^{2}\right)$ were evaporated on both sides of the composite electrolytes with $13 \mathrm{~mm}$ diameter. For comparison of the conductivity, the $\mathrm{PhSiO}_{3 / 2}$ pellet of the unmodified particles was prepared by pressing at $600 \mathrm{MPa}$ and room temperature to avoid the dehydration polycondensation by hot-pressing. In this case, carbon paper was used as the electrode for conductivity
( a )<smiles>CCC1C[N+](C)(C)CC1CC</smiles>

PDDA (b)<smiles>CCC(C)c1ccc(S(=O)(=O)[O-])cc1</smiles>

PSS

\section{(c)}

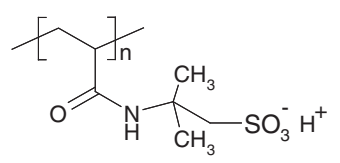

PAMPS
Fig. 1. Chemical structures of polyelectrolytes used for LbL assembly. measurement due to the low conductivity of the pelletized $\mathrm{PhSiO}_{3 / 2}$ sample. Temperature and relative humidity dependences of conductivity were measured after the retention time of $90 \mathrm{~min}$ at each measurement condition. The morphology of the composites was observed by a field emission scanning electron microscopy (FE-SEM, S-4800, Hitachi High-Technologies).

PAMPS thin film was spin-coated on a non-alkaline glass substrate using $1.5 \mathrm{wt}$ \% PAMPS aqueous solution. The combshaped gold electrode was evaporated on the PAMPS thin film. The in-plane proton conductivity $(\sigma)$ of thin film deposited on a glass substrate was calculated as

$$
\sigma=\frac{W}{L} \times \frac{1}{R d}
$$

where $W$ is a distance between teeth of comb-shaped electrode, $L$ is a total electrode length of the comb-shaped electrode, $R$ is the resistance, and $d$ is the total thickness of a thin film.

\subsection{Estimation of proton conductivity of composite electrolyte}

A GEM equation reported by McLachlan et al. ${ }^{19)}$ was applied in the estimation of proton conductivity of the percolated PAMPS-multilayer in the composite electrolyte. The conductivity of a multilayer in the composite was estimated as follows;

$$
\begin{aligned}
& \phi_{1} \frac{\sigma_{1}^{1 / s}-\sigma_{\mathrm{m}}^{1 / s}}{\sigma_{1}^{1 / s}+A \sigma_{\mathrm{m}}^{1 / s}}+\phi_{2} \frac{\sigma_{2}^{1 / t}-\sigma_{\mathrm{m}}^{1 / t}}{\sigma_{2}^{1 / t}+A \sigma_{\mathrm{m}}^{1 / t}}=0 \\
& A=\left(1-\phi_{\mathrm{c}}\right) / \phi_{\mathrm{c}} \\
& \phi_{2}=1-\left(\frac{r}{R}\right)^{3}
\end{aligned}
$$

where $\phi_{1}\left(\phi_{1}+\phi_{2}=1\right)$ is the volume fraction of $\mathrm{PhSiO}_{3 / 2}$ particles, and $\phi_{2}$ is the volume fraction of the PAMPS-multilayer calculated from Eq. (4). $\phi_{2}$ was calculated from the relationship between the $\mathrm{PhSiO}_{3 / 2}$ particle radius $r$ and the multilayerdeposited $\mathrm{PhSiO}_{3 / 2}$ radius $R(R=r+d)$, and $d$ is the thickness of the PAMPS-multilayer estimated from the frequency changes of quartz crystal microbalance (QCM). $\sigma_{1}$ is the experimentally obtained conductivity of $\mathrm{PhSiO}_{3 / 2}$ particles, $\sigma_{2}$ is the supposed conductivity of the PAMPS-multilayer as a fitting parameter, and $\sigma_{\mathrm{m}}$ is the conductivity of the composite electrolyte measured by an AC impedance method. $\phi_{\mathrm{c}}$ is a critical volume fraction for high conductive phase (percolation threshold value). $t$ for the low conductivity region $\left(\phi<\phi_{\mathrm{c}}\right)$ and $s$ for the high conductivity region $\left(\phi>\phi_{\mathrm{c}}\right)$ are a critical exponent related to the tendency of the conductivity changes of the composite electrolyte.

\section{Results and discussion}

\subsection{Preparation of the composite electrolyte}

Figure 2(a) shows whole appearance of the composite electrolyte using the $\mathrm{PhSiO}_{3 / 2}$ with $700 \mathrm{~nm}$ of average particle diameter as a typical example. All the composites prepared from the size-controlled $\mathrm{PhSiO}_{3 / 2}$ particles were transparent and just about colorless. Figures 2(b) and 2(c) show the cross-sectional SEM images of the composite electrolytes obtained from $\mathrm{PhSiO}_{3 / 2}$ particles with average diameters of 700 and $250 \mathrm{~nm}$, respectively. The plastically-deformed $\mathrm{PhSiO}_{3 / 2}$ particles were observed in both SEM images. Grain sizes of the deformed particles agreed with the average diameter of $\mathrm{PhSiO}_{3 / 2}$ particle used as a core particle. In contrast, the hot-pressed pellet of unmodified $\mathrm{PhSiO}_{3 / 2}$ particles did not show the grain boundary in the cross-sectional image. It means that the condensation reaction of the silanol groups of $\mathrm{PhSiO}_{3 / 2}$ particles and/or fusion between $\mathrm{PhSiO}_{3 / 2}$ particles occur during a hot-pressing. How- 

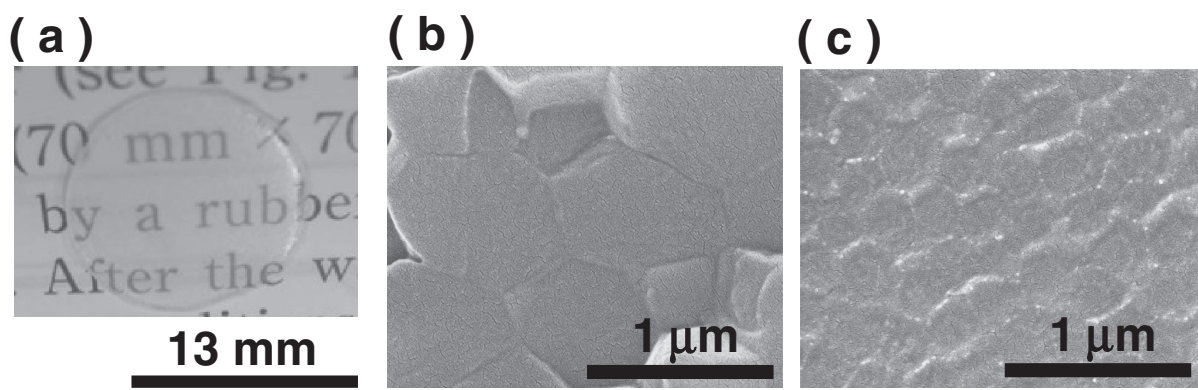

Fig. 2. (a) Whole image of the composite electrolyte prepared by hot-pressing at $120^{\circ} \mathrm{C}$. Cross-sectional SEM images of the multilayer-percolated composite electrolytes; the average core particle diameters are (b) $700 \mathrm{~nm}$ and (c) $250 \mathrm{~nm}$.

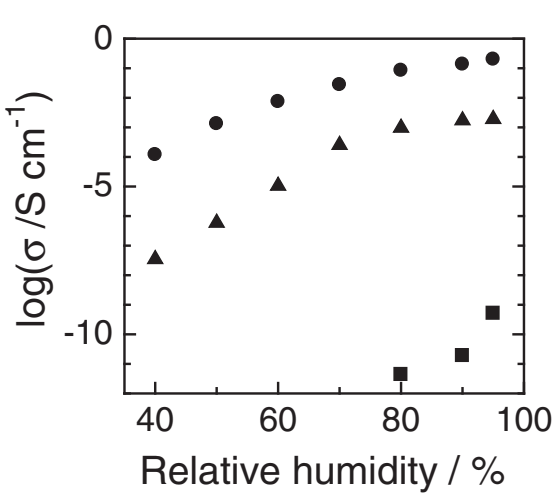

Fig. 3. Relative humidity dependences of proton conductivity at $80^{\circ} \mathrm{C}$ for the PAMPS film spin-coated on a non-alkaline glass substrate ( $)$, the composite electrolyte using $\mathrm{PhSiO}_{3 / 2}$ particles with an average diameter of $250 \mathrm{~nm}(\boldsymbol{\Lambda})$ and the pelletized sample of unmodified $\mathrm{PhSiO}_{3 / 2}$ particles with an average diameter of $700 \mathrm{~nm}($

ever, the composite electrolytes clearly showed the grain boundary which was composed of the multilayer thin film deposited on the $\mathrm{PhSiO}_{3 / 2}$ as a proton conducting layer. These SEM images suggest that the proton conductive multilayer was concentrated in the particle interface and three-dimensionally percolated in the composite.

Figure 3 shows the relative humidity dependences of proton conductivity at $80^{\circ} \mathrm{C}$ for the spin-coated PAMPS thin film on a non-alkaline glass substrate, the composite electrolyte obtained from multilayer-deposited $\mathrm{PhSiO}_{3 / 2}$ particle, and the pelletized sample of unmodified $\mathrm{PhSiO}_{3 / 2}$. The PAMPS thin film showed proton conductivities about $\sim 2-4$ orders of magnitude higher than the composite including 11 vol. $\%$ of multilayer. The conductivity values of PAMPS thin film at $90 \%$ R.H. and 95\%R.H. agreed with those of bulk sample of PAMPS reported in Ref. 27). The apparent activation energy $(\Delta E)$ for proton conduction in the PAMPS thin film was $11-13 \mathrm{~kJ} \mathrm{~mol}^{-1}$ at $80-95 \%$ R.H. These $\Delta E$ values suggest that protons transfer through adsorbed water molecules, in addition this value is essentially the same as that $\left(25 \mathrm{~kJ} \mathrm{~mol}^{-1}\right)$ of the composite obtained from multilayer-deposited $\mathrm{PhSiO}_{3 / 2}$ particles. The difference of $\Delta E$ values was considered to be the cause of the ion complex between the sulfo groups of PAMPS and quaternary ammonium of PDDA, since the amount of free sulfo groups of PAMPS in the multilayer decreased by strong electrostatic interaction. Three-dimensionally-percolated PAMPS-multilayers of the composite probably form the channel of sulfo-groups of PAMPS at high humidity conditions, which is similar to the cluster channel composed of sulfo-groups of Nafion ${ }^{\circledR}$ membrane. On the other hand, the particle interface of the

\section{Core-shell particles}
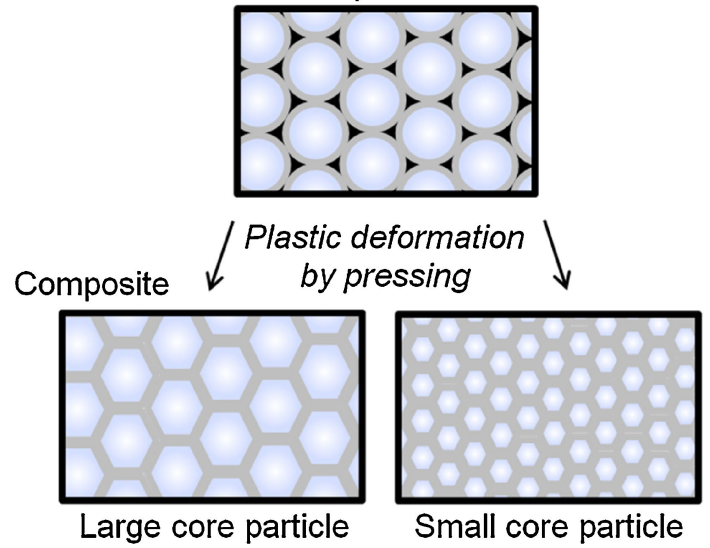

Fig. 4. (Color online) Schematic image of the percolation of the proton conductive paths in the composite electrolyte prepared from sizecontrolled core-shell particles by pressing.

pelletized $\mathrm{PhSiO}_{3 / 2}$ by pressing at room temperature showed low ion conductivity at $80^{\circ} \mathrm{C}$ because particle surface was composed of silanol groups and phenyl groups.

\subsection{Estimation of proton conductivity by GEM approximation}

Figure 4 shows the schematic image of the percolation of the proton conductive paths in the composite electrolyte. The void space between the $\mathrm{PhSiO}_{3 / 2}$ particles was completely filled during the plastic deformation. Therefore, the composite electrolytes prepared from the core-shell particles consisted of two components; i) $\mathrm{PhSiO}_{3 / 2}$ particles as a core, and ii) proton conductive multilayer as a shell. In previous study, the apparent thickness of the Primer/PAMPS-multilayer was estimated to be $5 \mathrm{~nm}$ from the QCM results and the assumptive densities of polymer layer. ${ }^{11)}$ If the multilayer thickness is constant for all composite using the size-controlled $\mathrm{PhSiO}_{3 / 2}$, the volume fraction of the multilayer in composite depends on the core particle size.

The ionic/electric/thermal conductivities of composite generally depend on the volume fraction $\left(\phi_{\mathrm{i}}\right)$, conductivity of original material $\left(\sigma_{\mathrm{i}}\right)$, and dispersibility of materials. ${ }^{1)-3), 18)-24)}$ The conductivity of composite drastically changes near the $\phi_{\mathrm{c}}$, because the composite changes to be a high ion conductor by the percolation of ion conducting materials. In this section, proton conductivity of the percolated PAMPS-multilayer was discussed from simulation results based on the GEM approximation. On the GEM approximation, $\phi_{\mathrm{c}}, t$ and $s$, are important parameters. The percolation theory (scaling law) has been used to determine the critical exponent parameters, ${ }^{19), 22), 25), 26)}$ which was described as follows; 


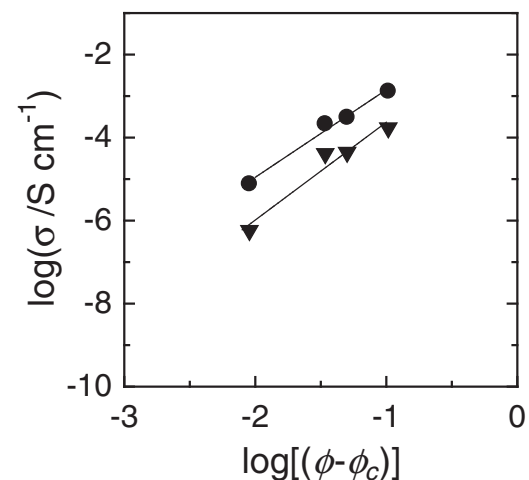

Fig. 5. Relationships between $\log \sigma$ at $80 \%$ R.H. and $\log \left(\phi-\phi_{\mathrm{c}}\right)$ in the range of $\phi_{2}>\phi_{\mathrm{c}}$ for the composite electrolytes composed of PDDA/ PSS/PDDA/PAMPS-multilayer deposited $\mathrm{PhSiO}_{3 / 2}$ particles; $(\bullet) 80^{\circ} \mathrm{C}$, ( $\mathbf{\nabla}) 30^{\circ} \mathrm{C}$.

$$
\begin{aligned}
& \sigma_{\mathrm{m}} \propto \sigma_{\mathrm{L}}\left(\phi_{\mathrm{c}}-\phi\right)^{-s} \text { for } \phi<\phi_{\mathrm{c}} \\
& \sigma_{\mathrm{m}} \propto \sigma_{\mathrm{H}}\left(\phi-\phi_{\mathrm{c}}\right)^{t} \quad \text { for } \phi>\phi_{\mathrm{c}}
\end{aligned}
$$

$\sigma_{\mathrm{L}}$ and $\sigma_{\mathrm{H}}$ are conductivities of low conduction phase and high conduction phase, respectively. Figure 5 shows the relationships between the $\log \sigma$ and the $\log \left(\phi-\phi_{\mathrm{c}}\right)$ for the composite electrolytes at $80 \%$ R.H at 80 and $30^{\circ} \mathrm{C}$. The lowest volume fraction of $0.75 \mathrm{vol} . \%\left(\phi_{2}=0.0075\right)$ for the composite using the $\mathrm{PhSiO}_{3 / 2}$ with $4.0 \mu \mathrm{m}$ of particle diameter was used as the $\phi_{\mathrm{c}}$. The critical exponents, $t$, were estimated to be about 2.1 and 2.3 for the GEM approximation at 80 and $30^{\circ} \mathrm{C}$, respectively, from the slope of Fig. 5. On the other hand, the critical exponents related with low conductive region, $s$, could not be calculated from experiment results in this study. However, the effect of $s$ was negligible small because the low conductive region was very narrow due to the very low $\phi_{c}$. In this simulation, $s$ was assumed to be 1 for the GEM approximation. Figure 6 shows the fitting curves estimated by the GEM equation for the proton conductivity of composite electrolytes at $80 \%$ R.H. The experimental values of the PAMPS thin film and the pelletized $\mathrm{PhSiO}_{3 / 2}$ were used as the conductivities for $\phi_{2}=1$ and $\phi_{2}=0$ $\left(\phi_{1}=1\right)$. However, the assumed value of $1 \times 10^{-12} \mathrm{~S} \mathrm{~cm}^{-2}$ as $\phi_{1}$ was used for the fitting of $30^{\circ} \mathrm{C}$ because the conductivity measurement for the $\mathrm{PhSiO}_{3 / 2}$ pellet at $30^{\circ} \mathrm{C}$ and $80 \%$ R.H. was not available due to exceptionally low conductivity. The parameters for GEM equation are $\sigma_{1}=8.5 \times 10^{-2} \mathrm{~S} \mathrm{~cm}^{-1}$, $\sigma_{2}=4 \times 10^{-12} \mathrm{~S} \mathrm{~cm}^{-1}$ for $80^{\circ} \mathrm{C}$, and $\sigma_{1}=6.5 \times 10^{-2} \mathrm{~S} \mathrm{~cm}^{-1}$, $\sigma_{2}=10^{-12} \mathrm{~S} \mathrm{~cm}^{-1}$ for $30^{\circ} \mathrm{C}$. From fitting curves, it was expected that the interfacial conducting paths had same level of proton conductivity with the spin-coated PAMPS film.

Figure 7 shows the relationships between the $\log \sigma$ and the $\log \left(\phi-\phi_{\mathrm{c}}\right)$ for the composite electrolytes at $80^{\circ} \mathrm{C}$. The $t$ was estimated to be about 2.1 for $70-95 \%$ R.H. and 1 for $50 \%$ R.H. at $80^{\circ} \mathrm{C}$ from the slope of Fig. 7. The difference of slopes at $70-95 \%$.R.H. and 50\% R.H. means the increasing rate of proton conductivity with respect to the volume fraction of multilayer in the composite electrolyte. This phenomenon probably related to the amount of adsorbed water in PAMPS, because the PAMPS polymer with 5-6 water molecules $\left(\mathrm{H}_{2} \mathrm{O}\right)$ per sulfo group $\left(-\mathrm{SO}_{3}{ }^{-}\right)$showed high proton conductivity at $22^{\circ} \mathrm{C}^{28)}$ The PAMPS polymer adsorbs $3 \mathrm{H}_{2} \mathrm{O} /-\mathrm{SO}_{3}{ }^{-}$at $50 \%$ R.H., $5 \mathrm{H}_{2} \mathrm{O} /$ $-\mathrm{SO}_{3}{ }^{-}$at $70 \%$ R.H. and $6 \mathrm{H}_{2} \mathrm{O} /-\mathrm{SO}_{3}{ }^{-}$at $80 \%$ R.H., in addition the $\Delta \mathrm{E}$ values are about $38 \mathrm{~kJ} \mathrm{~mol}^{-1}$ for $3 \mathrm{H}_{2} \mathrm{O} /-\mathrm{SO}_{3}{ }^{-}$and $19 \mathrm{~kJ} \mathrm{~mol}^{-1}$ for $<5 \mathrm{H}_{2} \mathrm{O} /-\mathrm{SO}_{3}{ }^{-}$. Figure 8 shows the fitting curves estimated by the GEM equation for the proton conductivity of composite electrolytes at $80^{\circ} \mathrm{C}$. The parameters
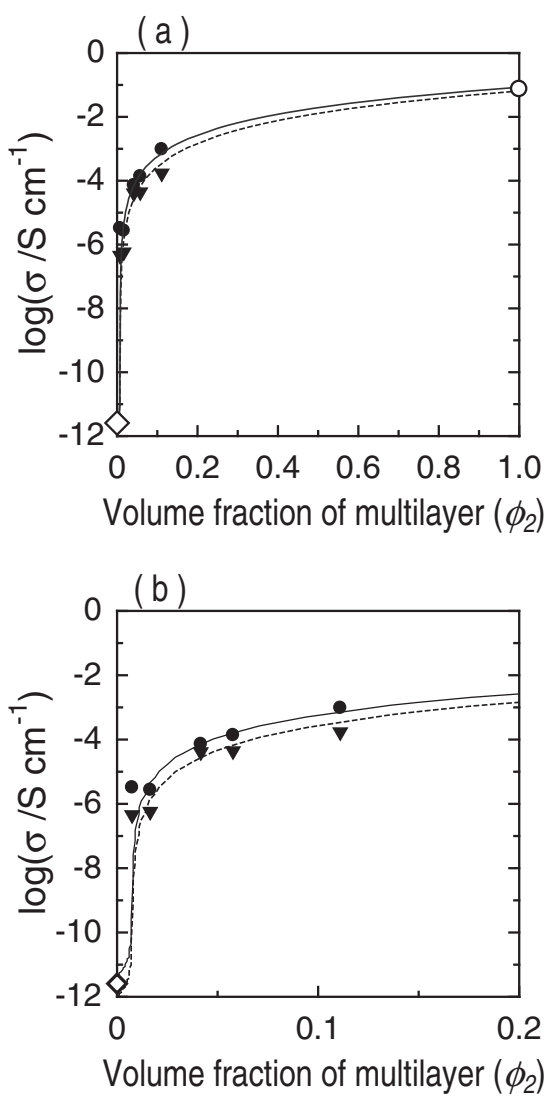

Fig. 6. Volume fraction dependences of proton conductivities at $80 \%$ R.H. for the composite electrolyte; $80^{\circ} \mathrm{C}(\bigcirc)$ and $30^{\circ} \mathrm{C}(\boldsymbol{\nabla})$. The fitting curves for $80^{\circ} \mathrm{C}$ (solid line) and $30^{\circ} \mathrm{C}$ (broken line) were calculated by the GEM equation in the range from (a) $\phi_{2}=0$ to 1 , and (b) $\phi_{2}=0$ to 0.2 . The proton conductivities of the PAMPS thin film $(\bigcirc)$ and the pelletized $\mathrm{PhSiO}_{3 / 2}(\diamond)$ were measured at $80^{\circ} \mathrm{C}$ and $80 \%$ R.H.

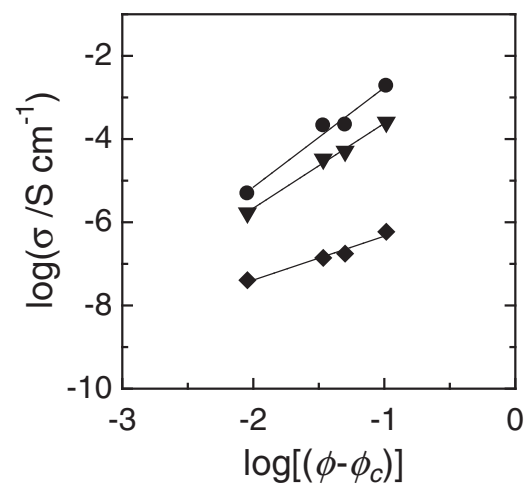

Fig. 7. Relationships between $\log \sigma$ at $80^{\circ} \mathrm{C}$ and $\log \left(\phi-\phi_{\mathrm{c}}\right)$ in the range of $\phi_{2}>\phi_{\mathrm{c}}$ for the composite electrolytes composed of PDDA/PSS/PDDA/PAMPS-multilayer deposited $\mathrm{PhSiO}_{3 / 2}$ particles; (๑) 95\%R.H., ( $\boldsymbol{\nabla}) 70 \%$ R.H. and $(\diamond) 50 \%$ R.H.

for GEM equation are $\sigma_{1}=0.2 \mathrm{~S} \mathrm{~cm}^{-1}, \sigma_{2}=5 \times 10^{-10} \mathrm{~S} \mathrm{~cm}^{-1}$ for 95\%R.H., $\sigma_{1}=2.8 \times 10^{-2} \mathrm{~S} \mathrm{~cm}^{-1}, \sigma_{2}=10^{-12} \mathrm{~S} \mathrm{~cm}^{-1}$ for 70\%R.H., and $\sigma_{1}=5.2 \times 10^{-6} \mathrm{~S} \mathrm{~cm}^{-1}, \sigma_{2}=10^{-12} \mathrm{~S} \mathrm{~cm}^{-1}$ for $50 \%$ R.H. It was estimated that the percolated conducting paths in the composite had same level of proton conductivity with the PAMPS polymer at $70-95 \%$ R.H. due to the hydration of sulfo groups of PAMPS. The hydrated sulfo groups in PAMPSmultilayer form the cluster channel in the particle interface for proton hopping by vehicle mechanism. It was anticipated from 

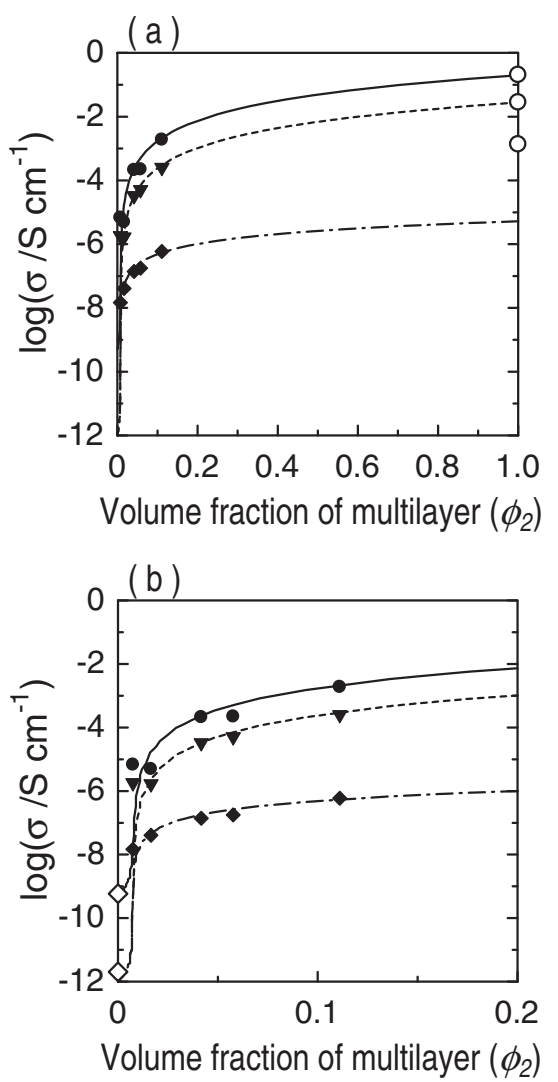

Fig. 8. Volume fraction dependences of proton conductivities at $80^{\circ} \mathrm{C}$ for the composite electrolyte; 95\%R.H. ( ), 70\%R.H. ( $\nabla)$ and 50\%R.H. $(\diamond)$. The fitting curves for 95\%R.H. (solid line), 70\%R.H. (broken line) and $50 \%$ R.H. (chain line) were calculated by the GEM equation in the range from (a) $\phi_{2}=0$ to 1 , and (b) $\phi_{2}=0$ to 0.2 . The proton conductivities of the PAMPS thin film $(\bigcirc)$ and the pelletized $\mathrm{PhSiO}_{3 / 2}$ $(\diamond)$ were measured at $80^{\circ} \mathrm{C}$.

GEM fitting that the proton conductivity of the composite composed of the Primer/PAMPS-multilayer achieves 0.01 $\mathrm{S} \mathrm{cm}^{-1}$ at $80^{\circ} \mathrm{C}$ and $95 \%$ R.H., when the core particle size decreases less than $100 \mathrm{~nm}\left(\phi_{2}=0.25\right)$. However, the interfacial conductivity at $50 \%$ R.H. was calculated to be 2 orders of magnitude lower than the spin-coated PAMPS polymer. The PAMPS-multilayer in the composite needs higher humidity conditions than the PAMPS polymer to form the high proton conducting channel, because PAMPS-multilayer was composed of the hydrophilic polymer electrolytes, PDDA, PSS and PAMPS. The mixing procedure using $\mathrm{LbL}$ assembly technique is an effective method to design the ion conductivity and chemical durability of inorganic-organic composite electrolytes. In addition, the amount of polymer electrolyte can be decreased by the use of polymer electrolyte as an ultrathin multilayer, which allows the use of various kinds of electrolytes and costeffectiveness.

\section{Conclusion}

Composite electrolytes were prepared using the size controlled $\mathrm{PhSiO}_{3 / 2}$ particles with the PAMPS-multilayer. The PAMPSmultilayer was successfully percolated in the composite by this composite procedure based on LbL assembly, and the ultrathin PAMPS-multilayer performed as the proton conducting path. The potential of high proton conductivity was estimated from the GEM approximation for the composite electrolyte at high humidity conditions. The percolation of PAMPS-multilayers in the composite electrolyte was supported by numerical analysis based on the GEM equation.

Acknowledgement This work has been partly supported by the Japan Society for the Promotion of Science [Grant-in-Aid for Scientific Research (B), No. 20360298]. H. S. acknowledges Research Fellowship for Young Scientist DC2 (No. 22 6855) by the Japan Society for the Promotion of Science.

\section{References}

1) C. C. Liang, J. Electrochem. Soc., 120, 1289-1292 (1973).

2) T. Jow and J. B. Wagner, J. Electrochem. Soc., 126, 1963-1972 (1979).

3) K. Shahi and J. B. Wagner, J. Electrochem. Soc., 128, 6-13 (1981).

4) S. Furusawa, S. Miyaoka and Y. Ishibashi, J. Phys. Soc. Jpn., 60, 1666-1671 (1991).

5) S. H. Chung, Y. Wang, L. Persi, F. Croce, S. G. Greenbaum, B. Scrosati and E. Plichta, J. Power Sources, 97, 644-648 (2001).

6) P. Knauth, J.-M. Debierre and G. Albinet, Solid State Ionics, 121, 101-106 (1999).

7) H. Maekawa, T. Iwatani, H. Shen, T. Yamamura and J. Kawamura, Solid State Ionics, 178, 1637-1641 (2008).

8) P. Raghavan, X Zhao, J.-K. Kim, J. Manuel, G. S. Chauhan, J.-H. Ahn and C. Nah, Electrochim. Acta, 54, 228-234 (2008).

9) A. A. Argun, J. N. Ashcraft and P. T. Hammond, Adv. Mater., 20, 1539-1543 (2008).

10) Y. Daiko, K. Katagiri, K. Shimoike, M. Sakai and A. Matsuda, Solid State Ionics, 178, 621-625 (2007).

11) H. Sakamoto, Y. Daiko, K. Katagiri, H. Muto, M. Sakai and A. Matsuda, Solid State Ionics, 181, 210-214 (2010).

12) Y. Daiko, S. Sakakibara, H. Sakamoto, K. Katagiri, H. Muto, M. Sakai and A. Matsuda, J. Am. Ceram. Soc., 92, S185-S188 (2009).

13) H. Sakamoto, Y. Daiko, K. Katagiri, H. Muto, M. Sakai and A. Matsuda, J. Power Sources, 195, 5942-5946 (2010).

14) R. Blender and W. Dieterich, J. Phys. C: Solid State Phys., 20, 6113-6126 (1987).

15) H. E. Roman and M. Yussouff, Phys. Rev. B, 36, 7285-7288 (1987).

16) H. E. Roman, A. Bunde and W. Dieterich, Phys. Rev. B, 34, 3439-3445 (1986).

17) A. G. Rojo and H. E. Roman, Phys. Rev. B, 37, 3696-3698 (1988).

18) D. S. McLachlan, M. Blaskiewicz and R. E. Newnham, J. Am. Ceram. Soc., 73, 2187-2203 (1990).

19) J. Wu and D. S. McLachlan, Phys. Rev. B, 56, 1236-1248 (1997).

20) K. Nozaki and T. Itami, J. Phys.: Condens. Matter, 16, 77637767 (2004).

21) K. Nozaki and T. Itami, J. Phys.: Condens. Matter, 18, 36173627 (2006).

22) K. Nozaki and T. Itami, J. Phys.: Condens. Matter, 18, 21912198 (2006).

23) F. C. Fonseca and R. Muccillo, Solid State Ionics, 166, 157165 (2004)

24) Ye. P. Mamunya, V. V. Davydenko, P. Pissis and E. V. Lebedev, Eur. Polym. J., 38, 1887-1897 (2002).

25) D. van der Putten, J. T. Moonen, H. B. Brom, J. C. M. Brokken-Zijp and M. A. J. Michels, Phys. Rev. Lett., 69, 494497 (1992).

26) M. T. Connor, S. Roy, T. A. Ezquerra and F. J. B. Calleja, Phys. Rev. B, 57, 2286-2294 (1998).

27) L. E. Karlsson, B. Wesslén and P. Jannasch, Electrochim. Acta, 47, 3269-3275 (2002).

28) J.-P. Randin, J. Electrochem. Soc., 129, 1215-1220 (1982). 